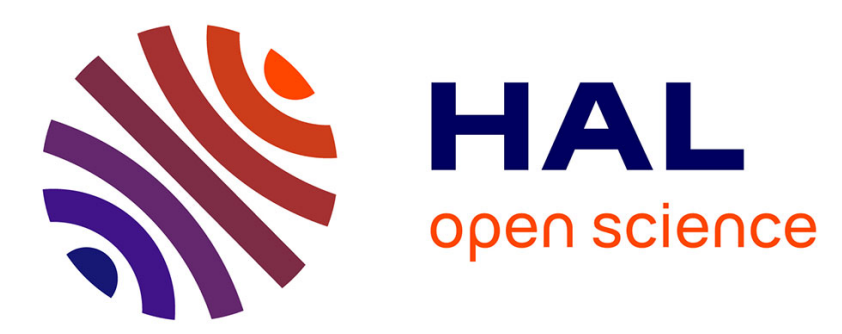

\title{
Short-Fractional Hop Whistler Rate Observed by the Low-Altitude Satellite DEMETER at the End of the Solar Cycle 23
}

\author{
Michel Parrot, Jean-Louis Pinçon, D. Shklyar
}

\section{To cite this version:}

Michel Parrot, Jean-Louis Pinçon, D. Shklyar. Short-Fractional Hop Whistler Rate Observed by the Low-Altitude Satellite DEMETER at the End of the Solar Cycle 23. Journal of Geophysical Research Space Physics, 2019, 124 (5), pp.3522-3531. 10.1029/2018JA026176 . insu-02157528

\section{HAL Id: insu-02157528 \\ https://hal-insu.archives-ouvertes.fr/insu-02157528}

Submitted on $10 \mathrm{Jul} 2019$

HAL is a multi-disciplinary open access archive for the deposit and dissemination of scientific research documents, whether they are published or not. The documents may come from teaching and research institutions in France or abroad, or from public or private research centers.
L'archive ouverte pluridisciplinaire HAL, est destinée au dépôt et à la diffusion de documents scientifiques de niveau recherche, publiés ou non, émanant des établissements d'enseignement et de recherche français ou étrangers, des laboratoires publics ou privés.

$$
\text { Copyright }
$$




\section{JGR Space Physics}

\section{RESEARCH ARTICLE 10.1029/2018JA026176 \\ Key Points: \\ - Short-fractional hop whistler rate in \\ Short-Fractional Hop Whistler Rate Observed by the Low- Altitude Satellite DEMETER at the End of the Solar Cycle 23} the upper ionosphere is estimated for the first time with a neural network

- This short-fractional hop whistler rate during nighttime is between 1 and $6 \mathrm{~s}^{-1}$ with an average value equal to $3 \mathrm{~s}^{-1}$

- This short-fractional hop whistler rate is anticorrelated with the solar flux

Supporting Information:

- Figure S1

- Figure S2

- Figure S3

- Figure S4

- Figure S5

- Figure S6

Correspondence to:

M. Parrot,

mparrot@cnrs-orleans.fr

Citation:

Parrot, M., Pinçon, J.-L., \& Shklyar, D. (2019). Short-fractional hop whistler rate observed by the low-altitude satellite DEMETER at the end of the solar cycle 23. Journal of Geophysical Research: Space Physics, 124, 3522-3531. https://doi.org/10.1029/ 2018JA026176

Received 9 OCT 2018

Accepted 15 MAR 2019

Accepted article online 9 APR 2019

Published online 8 MAY 2019

(c)2019. American Geophysical Union. All Rights Reserved.

\author{
M. Parrot ${ }^{1}$ iD, J.-L. Pinçon' ${ }^{1}$ D, and D. Shklyar ${ }^{2,3}$ iD \\ ${ }^{1}$ University of Orléans, LPC2E/CNRS, Orléans, France, ${ }^{2}$ Space Research Institute, Russian Academy of Sciences, Moscow, \\ Russia, ${ }^{3}$ National Research University Higher School of Economics, Moscow, Russia
}

Abstract For the first time an evaluation of the whistler rate around the Earth is performed using results from the neural network aboard the microsatellite DEMETER. It is shown that the rate of whistlers with low dispersion calculated all around the Earth as a function of longitude vary between 1 and $6 \mathrm{~s}^{-1}$ during nighttime (22.30 LT) and between 0.5 and $0.7 \mathrm{~s}^{-1}$ during daytime (10.30 LT). The whistler rate is anticorrelated with the $F 10.7-\mathrm{cm}$ solar flux. A decrease by $25 \%$ of the solar flux corresponds to an increase of $62 \%$ (26\%) of the averaged whistler rate calculated for the entire Earth during nighttime (daytime). Using this averaged whistler rate, the global lightning rate is estimated to be of the order of $123 \mathrm{~s}^{-1}\left(27 \mathrm{~s}^{-1}\right)$ during nighttime (daytime). The main conclusion concerns the precipitation of the electrons in the radiation belt by interaction with the whistlers. It is shown that the decrease of the lightning activity at solar minimum (shown with the help of the Schumann resonances) is largely counterbalanced by the increase of the whistler rates in the upper part of the ionosphere due to the decrease of the ionospheric absorption.

\section{Introduction}

Storey (1953) first showed that waves (the so-called whistlers) coming from the lightning strokes propagate in the ionosphere and magnetosphere to be recorded in the opposite hemisphere with frequency dispersion. Since his pioneering work, a huge number of papers has been published concerning the most important phenomenon occurring in the Earth's atmosphere (about 2,000 thunderstorms are active at any time (Uman, 1986)). For example, contribution and review can be found in Helliwell (1965, 1993), Hayakawa (1995), Green and Inan (2006), Füllekrug et al. (2006), Siingh et al. (2008), and Kumar et al. (2018).

In this paper, we intend to evaluate the rate of the whistlers which are recorded in the upper part of the ionosphere using the RNF (Réseau de Neurones Formel) experiment onboard the low altitude microsatellite DEMETER (Detection of Electro-Magnetic Emissions Transmitted from Earthquake Regions). In the context of this paper, by whistler rate, we understand the number of short-fractional hop whistlers registered by the satellite per second. Short-fractional hop whistlers are those which have not crossed the magnetic equatorial plane but just coming from below the satellite (Smith \& Angerami, 1968). Whistlers are important because they induce electron precipitation from the radiation belts (see Inan et al., 2007; Gemelos et al., 2009; Bourriez et al., 2016, and references therein). Whistlers also significantly impact the overall wave intensity in the magnetosphere (Colman \& Starks, 2013; Němec et al., 2010; Záhlava et al., 2018). This is specially the case during nighttime when the wave attenuation in the ionosphere is lower (Cohen et al., 2012; Graf et al., 2013). Due to this attenuation, the relation between whistler rate observed in the ionosphere and the lightning stroke rate might be not straightforward (Christian, 2003). It has been even shown that some whistlers induced by lightning strokes occurring in the equatorial region never reach the magnetosphere (Shklyar et al., 2018).

The survey of the lightning activity, and then of the whistler rate, is of primary interest due to its relation to the global warming. Williams (1992) for the first time showed that surface temperature anomaly correlates with lightning activity. Using a model, Price and Rind (1994) have shown that there is an estimated 5\%-6\% change in global lightning rates for every $1{ }^{\circ} \mathrm{C}$ global warming. Other related studies can be found for example in Füllekrug and Fraser-Smith (1997), Reeve and Toumi (1999), Williams (2005), and Siingh et al. (2011).

Section 2 describes the data recorded by the RNF experiment onboard the microsatellite DEMETER. DEMETER was in operation at the end of the nontypical solar cycle 23 and the observed whistler rates as 
functions of solar activity are shown in section 3 . These results are discussed in section 4 whereas conclusions are given in section 5.

\section{The Data From the RNF Experiment}

The microsatellite DEMETER was in operation between July 2004 and December 2010 (Cussac et al., 2006). Its orbit was polar, circular, and with an altitude of about $700 \mathrm{~km}$. In addition, the orbit was nearly sun synchronous, that is, the measurements were performed at 10.30 and $22.30 \mathrm{LT}$. It must be noted that the nighttime measurements at 22.30 LT do not correspond to the period where the global thunderstorm activity is maximum: 14-19 LT (Price, 2006). Due to technical reasons these measurements covered the region between $-65^{\circ}$ and $+65^{\circ}$ of invariant latitude. A part of the scientific payload consisted of three electric field components to be used from DC up to $3.5 \mathrm{MHz}$ (Berthelier et al., 2006). For the Very Low Frequency (VLF) range, the electric field instrument was operated in two scientific modes: a continuous survey mode where spectra of one electric component were computed onboard up to $20 \mathrm{kHz}$ with a time resolution of $2 \mathrm{~s}$ and a triggered burst mode during which waveforms of one electric field component were recorded up to $20 \mathrm{kHz}$. The burst mode allows performing a spectral analysis with higher time and frequency resolution, but, due to telemetry restriction, it was not possible to run the burst mode everywhere around the Earth. As the time resolution of the survey spectrograms was not enough to evaluate the number of whistlers, it was decided to implement a neural network to directly perform onboard a continuous identification and classification of these phenomena with respect to their dispersion parameters. The RNF learning phase to determine the connection weights was conducted on the ground using the downloaded electric field burst data, and the final set of coefficients has been then uploaded in the onboard computer of the scientific payload. The time resolution of the resulting RNF data (number of whistlers in each dispersion class) is $0.1024 \mathrm{~s}$. Details about the RNF experiment can be found in Elie et al. (1999) and Buzzi (2007). They are summarized in the Appendix A. As input the RNF experiment uses an electric component of which the direction is well suited to detect whistlers as it is shown in the Appendix B.

In this study, we are concerned with low dispersion whistlers which have not crossed the magnetic equatorial plane: the short-fractional hop whistlers which are coming from below the satellite. Then, only the two first dispersion classes selected by the RNF have been considered. They correspond to a dispersion parameter $D_{\mathrm{o}}$ between 0 and $3.2 \mathrm{~s}^{1 / 2}$.

Using the data provided by the RNF, it is possible to obtain the geographic whistler distributions at the altitude of the satellite for different ranges of dispersion parameters and for both nighttime and daytime conditions. Figure 1 is an example of such a geographic whistler distribution derived from RNF results. It represents the map of the Earth where the number of whistlers with small dispersion parameters recorded by the RNF has been plotted using a color representation. The distribution is obtained considering all low dispersion whistlers $\left(0 \mathrm{~s}^{1 / 2}<D_{\mathrm{o}}<3.2 \mathrm{~s}^{1 / 2}\right)$ detected between 2005 and 2010 during nighttime conditions. This map is very different from a map of lightning activity (Christian, 2003). The dark blue color surrounding the geomagnetic equator illustrates the shielding effect due to the local magnetic field topology which prevents direct upward propagation of VLF waves through the ionosphere in most cases. This influence is strengthened at the location of the South Atlantic Magnetic Anomaly and prevents to observe most of the short-fractional hop whistlers corresponding to the lightning activity in a large part of the South America. Recently, Shklyar et al. (2018) claimed that this effect is also due to a strong collisional damping of the waves close to the equator. A similar work by Jacobson et al. (2018) also showed that penetration of lightningrelated sferics at low latitudes is attenuated by the $D$ region. Nevertheless, it must be noted that the number of whistlers detected at the equator in Figure 1 is small but nonnegligible, which agrees with previous observations in this area (see, for example, Sonwalkar et al. (1995) and Holzworth et al. (2011)).

DEMETER data files are organized by half orbits (there are daytime half orbits and nighttime half orbits). To calculate the whistler rate, each half orbit has been separated in several parts. First, we considered the North Hemisphere and the South Hemisphere and then in each hemisphere a division was done as function of the $L$ values, $L$ being the McIlwain parameter (McIlwain, 1961). Two parts have been considered: $L=3-5$ to count the whistler rate in a region corresponding to the outer radiation belt where the whistlers are expected to be efficient to trigger electron precipitation and $L=1-3$ to complete the hemisphere. The value $L=1$ corresponds to the magnetic equator on the Earth, whereas the value $L=5$ roughly corresponds to our limit of 


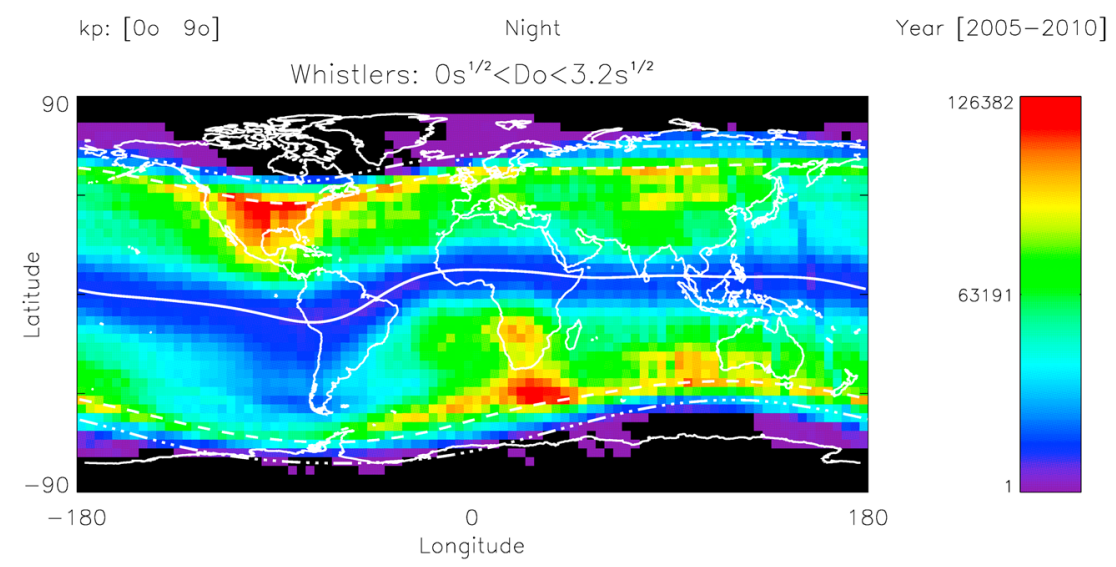

Figure 1. Geographic whistler distribution derived from the RNF experiment onboard DEMETER. It corresponds to whistlers with small dispersion parameters $\left(0 \mathrm{~s}^{1 / 2}<\mathrm{D}<3.2 \mathrm{~s}^{1 / 2}\right)$ detected between 2005 and 2010 during nighttime conditions whatever the value of $K p$. The colors correspond to the number of whistlers identified by the neural network. The geomagnetic equator, $L$ shell $=3$, and $L$ shell $=5$ are also represented using solid, dashed, and dash-dotted line styles, respectively. DEMETER does not record data when the invariant latitude is larger than $65^{\circ}$ which roughly corresponds to $L>5$.

measurement. Then, for each half orbit, the number of whistlers has been cumulated on both hemispheres when $L$ varies from 1 to 3 and divided by the time taken by the satellite to fly over this distance. This half orbit corresponds to a given geographic longitude, and the whistler rate is stored in a $10^{\circ}$ longitude bin. The same is done when $L$ varies from 3 to 5 . The process is repeated for all half orbits (with separation between day and nighttime). At the end, an average value of the whistler rate is calculated for all $10^{\circ}$ longitude bins.

\section{The Results}

An example of the whistler rates is given in Figure 2. It concerns data recorded in the North Hemisphere between $L=1$ and $L=3$ during nighttime in summer (July, August, and September). The data corresponding to these 3 months have been averaged. Histograms are given as functions of the geographic longitude for

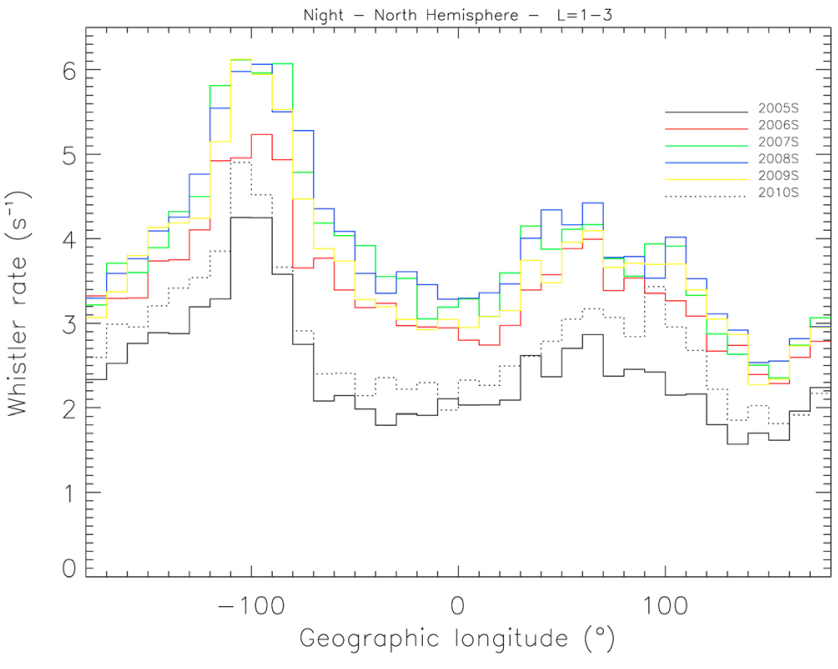

Figure 2. Whistler rates represented as functions of longitude for different summers between 2005 and 2010. The data correspond to the North Hemisphere for $L$ values between 1 and 3 during nighttime. The histograms are color coded for the different years as indicated in the insert (S means summer time). the years 2005-2010. Two main points come out. First, one can see that there are two peaks which are between $-120^{\circ}$ and $-80^{\circ}$ and between $30^{\circ}$ and $110^{\circ}$ in longitude. They correspond to the USA and to Russia, respectively. This is well in agreement with the whistler occurrence displayed in Figure 1. The second point is that the whistler rate depends on the year. For example, it is smaller for 2005 (high solar activity) and higher for 2008 (low solar activity).

Whistler rates for complete years (12-months averaged) are calculated for the entire Earth. We deliberately mix summer and winter in each hemisphere knowing that the thunderstorm activity is higher during summer season. The result is given in Figure 3 where the Earth is mapped in four panels. At high latitudes $(L=3-5)$ in the North Hemisphere the whistler rate is maximum between $-100^{\circ}$ and $0^{\circ}$ in longitude. For $L=1-3$ there are two peaks as in Figure 2. In the South Hemisphere for $L=1-3$, the whistler rate increases from $-60^{\circ}$, reaches a maximum around $20^{\circ}$ and then slowly decreases until $-100^{\circ}$. For $L=3-5$, the pattern is a little bit similar and fits well with the whistler occurrence shown in Figure 1. In all panels, there is a large difference between 2005 (high solar activity) and 2009 (low solar activity) and this difference is larger (a factor of 2) in this bottom panel. One also notices that this difference is null around $-100^{\circ}$ for $L=1-3$ in the South Hemisphere. 
(A)

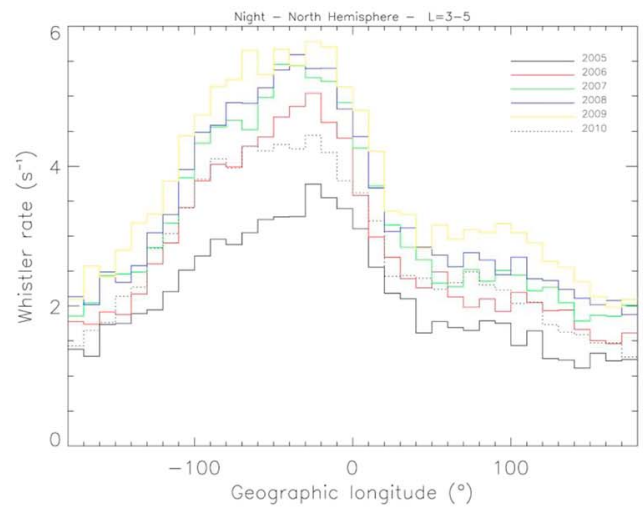

(B)

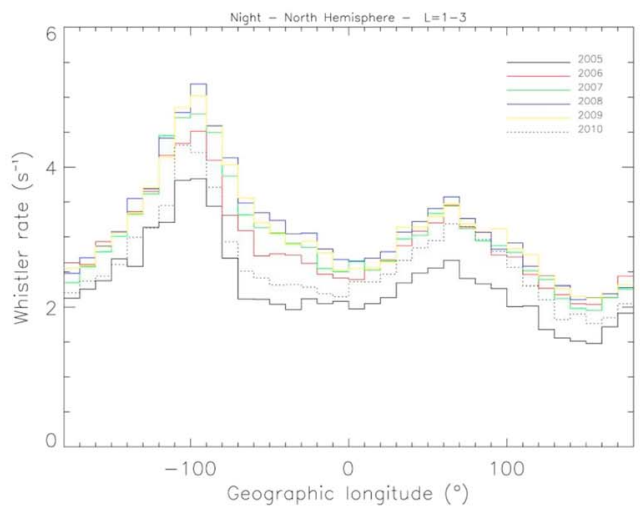

(C)
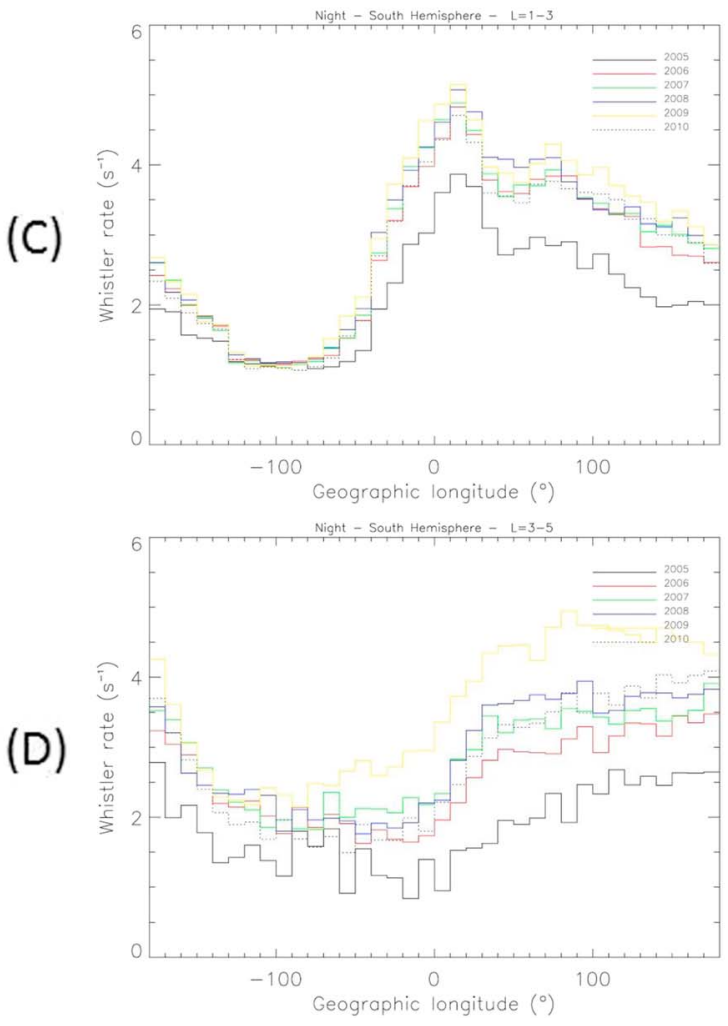

Figure 3. Whistler rates as function of longitude for different years. The presentation in each panel is similar to Figure 2, but the data are related to a complete year. From the top to the bottom, the four panels correspond to the North Hemisphere, $L=3-5$ and $L=1-3$, and South Hemisphere, $L=1-3$ and $L=3-5$.
Changing the intervals over $L$ shell in which the whistler rate is calculated to $L=1-2$ and $L=2-5$ leads to similar results as shown in Figure 3, except that the maximum of whistler rate during nighttime in the Northern Hemisphere moves to $-100^{\circ}$ geographic longitude (not shown here).

We have seen in Figures 2 and 3 that the whistler rates depend on the years, and in order to underline this effect of the solar cycle, we have averaged all the whistler rates over the longitudes, the two different $L$ intervals, and the two hemispheres. The result is shown in the top panel of Figure 4 (black curve) together with the variation of the $F 10.7-\mathrm{cm}$ solar flux (red curve). This red curve is obtained with a 12-month running average of the monthly values of the solar flux. The same processing is done for the daytime data, and the result is shown in the bottom panel of Figure 4. It is clearly seen that the whistler rate is anticorrelated with the solar flux in the nighttime (22.30 LT) and in the daytime (10.30 LT).

\section{Discussion}

Let us discuss the relation between the whistler rates (i.e., the number of short-fractional hop whistlers registered by the satellite per second), evaluated by RNF and the lightning rates. We begin with the global lightning rate over the Earth, $N_{L}(t)$, which is the total number of lightning strokes over the Earth per second. This quantity has the dimension of $\mathrm{s}^{-1}$ and is only the function of time; as such, it depends on all geophysical parameters: the phase of the solar cycle, geomagnetic activity, season, and time of the day. A more informative characteristic of lightning activity is the spatial density of lightning rate, $\mathrm{n}_{\mathrm{L}}$ (lat, long, $\mathrm{t}$ ), which is the lightning rate per unit surface. This quantity has the dimension of $\mathrm{s} / \mathrm{km}^{2}$ and, apart from the time, depends on the position on the Earth's surface.

As it is known, the electromagnetic energy induced by a lightning discharge can enter into the upper ionosphere and gives rise to sferics at quite large distance $l$ from lightning. In other words, each lightning stroke illuminates in the Earth-ionosphere waveguide the area $\mathrm{S} \sim \pi l^{2}$ that becomes the source of sferics, so the satellite registers all sferics that originate from lightning that take place over the area S. Since the time of emission propagation in the Earth-ionosphere waveguide is negligible, as well as the time of sferic propagation to the satellite heights, we may assume that there is no time delay between the lightning and sferic occurrence. Thus, the whistler rate registered by the satellite is $\mathrm{N}_{\mathrm{W}}$ (lat, long, $\mathrm{t}$ ) $=<\mathrm{n}_{\mathrm{L}}$ (lat, long, t) $>\cdot \mathrm{S}$, where $<\ldots>$ means the averaging over the area $\mathrm{S}$ centered on (lat, long). The quantity $\mathrm{N}_{\mathrm{W}}$ has the dimension of $\mathrm{s}^{-1}$, although it depends on the position, as well as the time, of course. We see that the global lightning rate $\mathrm{N}_{\mathrm{L}}(\mathrm{t})$ is connected with the space averaged whistler rate $\left.<\mathrm{N}_{\mathrm{W}}(\mathrm{t})\right\rangle=<\mathrm{N}_{\mathrm{W}}$ (lat, long, $\left.\mathrm{t}\right)>$ by the relation

$$
\mathrm{N}_{\mathrm{L}}(\mathrm{t})=<\mathrm{N}_{\mathrm{W}}(\mathrm{t})>\left(4 \pi \mathrm{R}_{\mathrm{E}}^{2} / \mathrm{S}\right)
$$

where $\langle\ldots\rangle$ means the averaging over the Earth's surface and $\mathrm{R}_{\mathrm{E}}$ is the Earth's radius. The distance $l$ at which the electromagnetic energy induced by a lightning discharge can enter into the magnetosphere, and thus, the area $\mathrm{S} \sim \pi l^{2}$ has been estimated by various authors, using different methods. Chum et al. (2006) gave the estimation $l \sim 1,500 \mathrm{~km}$ (see also Bourriez et al., 2016; Hayakawa et al., 1992 and Santolík et al., 2009). Vavilov and Shklyar (2014) gave the estimation of lightning-illuminated region in the Earth-ionosphere waveguide to be of the order of 4,000 km 
(A)

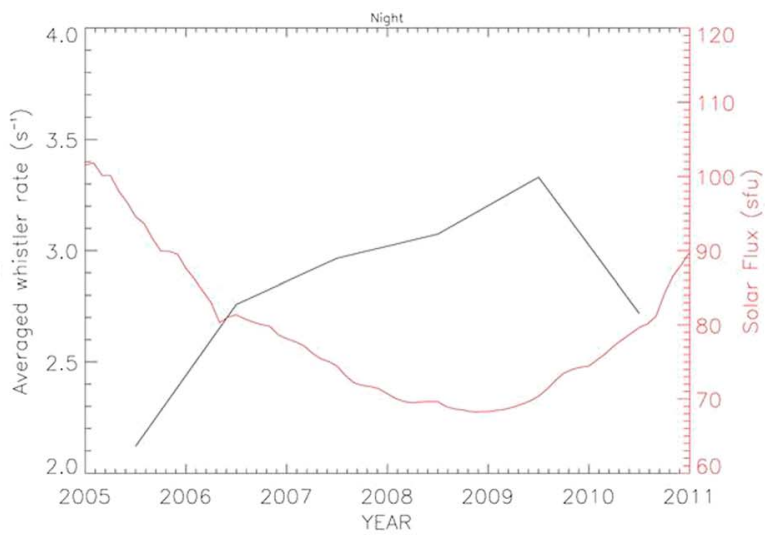

(B)

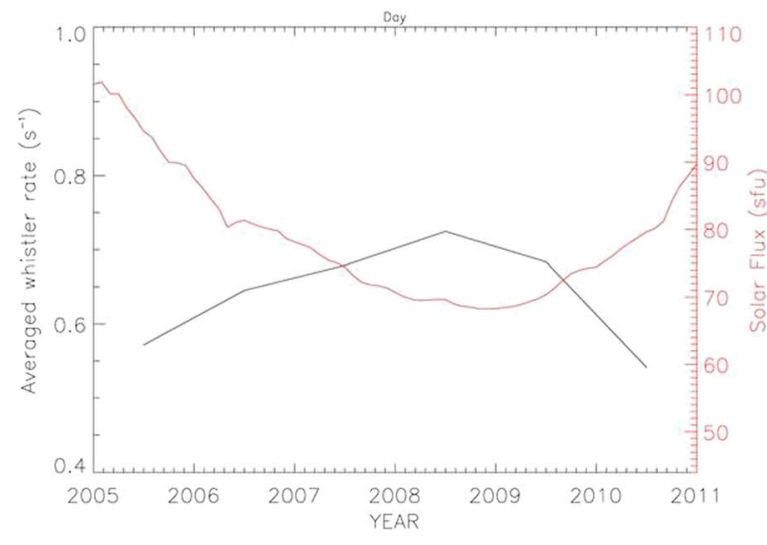

Figure 4. The black line represents the averaged whistler rate all around the Earth during nighttime (top panel) and daytime (bottom panel) as a function of the years between 2005 and 2010. The red line represents the corresponding solar flux. The F10.7-cm solar flux is given in solar flux units (a $\mathrm{sfu}=10^{-22} \mathrm{~W} \mathrm{~m}^{-2} \mathrm{~Hz}^{-1}$ ). in linear dimension, thus $l \sim 2,000 \mathrm{~km}$. This is in agreement with the work of Shklyar et al. (2004) which compares numerical simulation and observations of magnetospheric reflected whistlers. As we have seen above, a typical whistler rate $\mathrm{N}_{\mathrm{W}}(\mathrm{t})$ measured by DEMETER is of the order of $3 \mathrm{~s}^{-1}$ during nighttime. Using for estimation the values of $l \sim 2,000 \mathrm{~km}$ and the corresponding value of $\mathrm{S} \sim \pi l^{2}$, we get from (1) $\mathrm{N}_{\mathrm{L}} \sim 123 \mathrm{~s}^{-1}$, which is not far from the expected lightning stroke rate (Christian, 2003; Collier et al., 2011). For the daytime, $\mathrm{N}_{\mathrm{W}}(\mathrm{t})$ is of the order of $0.65 \mathrm{~s}^{-1}$ and then $\mathrm{N}_{\mathrm{L}} \sim 27 \mathrm{~s}^{-1}$. It must be noticed that this lightning rate $\mathrm{N}_{\mathrm{L}}$ is perhaps overestimated because, using C/NOFS data Burkholder et al. (2013) have observed whistlers at a distance $l$ much larger than $2,000 \mathrm{~km}$.

This is the first study which globally investigates the whistler rates around the Earth in the upper part of the ionosphere from a satellite, but in the past, whistler occurrences have been studied as function of the solar cycle at specific ground locations. Recording whistlers with low dispersion at Poitiers (France), Corcuff et al. (1966) have shown that the number of whistlers between 15 and 19 LT is more important during low solar activity than during high solar activity. Hayakawa et al. (1971) have studied the whistlers registered at Moshiri (Japan) during the solar cycle 1958-1968, and they have also observed an anticorrelation between the number of whistlers and the solar flux. A similar feature is reported by Ohta and Hayakawa (1990) who have compared the whistler rates measured in January during one solar cycle (1977-1987) at Yamaoka (geomag. lat. $\left.25^{\circ}, L=1.26\right)$.

The important question is to know if this anticorrelation between whistler rates and solar activity is due to a change of the lightning activity related to the solar cycle or to the change of the whistler propagation in the ionosphere. For example, it has been shown by Thomson et al. (2012) that during daytime, the height of the $D$ region (the lowest edge of the Earth's ionosphere) decreases when the sunspot number increases. The same effect was observed by Toledo-Redondo et al. (2012) but for nighttime. One could also understand that this study is certainly biased by the global warming which increases the lightning activity year by year (see section 1 ).

To our knowledge, there is no global analysis of the variation of the thunderstorm activity as function of the solar cycle, and it only exists partial studies concerning specific locations. These studies lead to different conclusions depending on these locations. In their reviews, Siingh et al. (2011) and Neto et al. (2013) noticed that the relation between sunspot number and lightning flash rate is not evident.

On one hand, Stringfellow (1974) has shown a clear correlation between lightning activity and sun spot numbers in Britain between 1930 and 1973, that is, over many solar cycles. Studying the lightning activity during 150 years in the eighteenth to the nineteenth centuries in Japan Miyahara et al. (2018) have found that this lightning activity increases as the solar activity increases.

On the other hand, with the measurement of potential gradient at Lerwick Observatory (Shetland) between 1978 and 1985, Harrison and Usoskin (2010) have observed that the lower troposphere atmospheric electricity increases during solar minimum. Studying lightning strokes in Trivandrum (India) near the magnetic equator between 1853 and 2005, Girish and Eapen (2008) claimed that the lightning activity maximizes during the minimum periods of sunspot activity and minimizes during the sunspot maximum period. But they only check in April and they count a number of days where thunderstorm is present.

Using lightning data from the Lightning Imaging Sensors experiment onboard the satellite Tropical Rainfall Measuring Mission above India and South East Asia, Siingh et al. (2013) do not show statistically significant correlations between the lightning flashes and the F10.7-cm flux during the complete solar cycle 23 . Counting the lightning strokes recorded by the World Wide Lightning Location Network in the area 
determined by $40-80^{\circ} \mathrm{N}$ and $60-180^{\circ} \mathrm{E}$ in $2009-2016$, Tarabukina and Kozlov Vladi (2017) have not seen any correlation or anticorrelation with the solar cycle.

Recently, in a review, Kumar et al. (2018) noticed that the relation between thunderstorm activity and solar activity most likely depends on the location of observing stations on the Earth where cosmic ray flux and local meteorological conditions may dominate. This could explain that in various studies, the thunderstorm activity is sometimes correlated, sometimes anticorrelated to the solar activity (see their Table 1).

Another possibility is to compare our results with the evolution of the characteristics of the Schumann resonances (SR) as functions of the solar cycles. The SR are linked to the thunderstorm activity because they are induced by lightning waves propagating in the waveguide formed by the Earth's surface and the bottom of the ionosphere (Nickolaenko \& Hayakawa, 2002). At the Ukrainian Antarctic station "Akademik Vernadsky" (65.25 ${ }^{\circ} \mathrm{S}$ and $64.25{ }^{\circ} \mathrm{W}$ ), Nickolaenko et al. (2015) have observed from March 2002 to February 2012 (i.e., during the same solar cycle 23) a decrease of the SR intensities (first SR mode) when F10.7-cm decreases. There is also a decrease of the SR frequency of the first mode. A similar decrease of the SR frequency has been also reported by Sátori et al. (2005). But if we can attribute the change of the SR intensities to the change of the lightning activity, the change of the SR frequencies is more due to a change of the propagation in the waveguide, that is, a change of the height of the ionosphere as noticed above.

The conclusion of these previous studies is that, globally, there is a correlation between lightning activity and the solar cycle. Looking at Figure 1 of Nickolaenko et al. (2015), one can see that the drop in F10.7 cm of $25 \%$ between 2005 and 2009 corresponds also to a drop in the SR intensities of the order of $25 \%$ during the same period. Meanwhile, we observe an increase of $62 \%$ in the averaged whistler rates during nighttime (top panel of Figure 4) and an increase of $26 \%$ during daytime (bottom panel of Figure 4). The only difference between lightning rate and whistler rate can be assigned to the ionospheric absorption which decreases between 2005 and 2009 because the density is much lower. Then we can say that the ionospheric absorption is the dominating factor in the long-term variation of the whistler rate as it was already noticed by Ohta and Hayakawa (1990).

\section{Conclusions}

The number of whistlers with low dispersion registered by the RNF experiment aboard the microsatellite DEMETER in the upper ionosphere $(660 \mathrm{~km})$ has been globally investigated for the first time. The period of observation corresponds to the lower part of the unusual solar cycle 23 (the lowest solar flux since satellites have been launched). Whistler rates are calculated all around the Earth between $L=1$ and $L=5$ in the two hemispheres as functions of geographic longitude during nighttime (22.30 LT) and daytime (10.30 LT). It is shown as follows:

(i) During nighttime, the whistler rate in the upper ionosphere is between 1 and $6 \mathrm{~s}^{-1}$ with an average value of the order of $3 \mathrm{~s}^{-1}$. During daytime, the whistler rate is between 0.5 and $0.7 \mathrm{~s}^{-1}$ with an average value of the order of $0.65 \mathrm{~s}^{-1}$. This whistler rate varies with longitude as a function of lightning activity in the atmosphere as expected.

(ii) The whistler rate varies as a function of the year, and between 2005 (solar maximum during the mission) and 2009 (solar minimum), it could increase by a factor of 2 (bottom panel of Figure 3).

(iii) The whistler rate is anticorrelated with the F10.7-cm solar flux (Figure 4). During night (day) time, this whistler rate increases by $62 \%$ (26\%) between 2005 and 2009 whereas the solar flux decreases by $25 \%$.

From previous studies, it has been shown that the lightning activity increases/decreases with the solar flux. This is important for the electron precipitation by whistler waves because the decrease of the lightning activity during the low part of the solar cycle is largely offset by the increase of the whistler rates in the upper ionosphere.

\section{Appendix A: The RNF Experiment}

In the frame of DEMETER, the survey of whistler's properties is of obvious interest. However, a statistical study of whistlers requires the analysis of all observed whistlers whereas, according to the storage and 


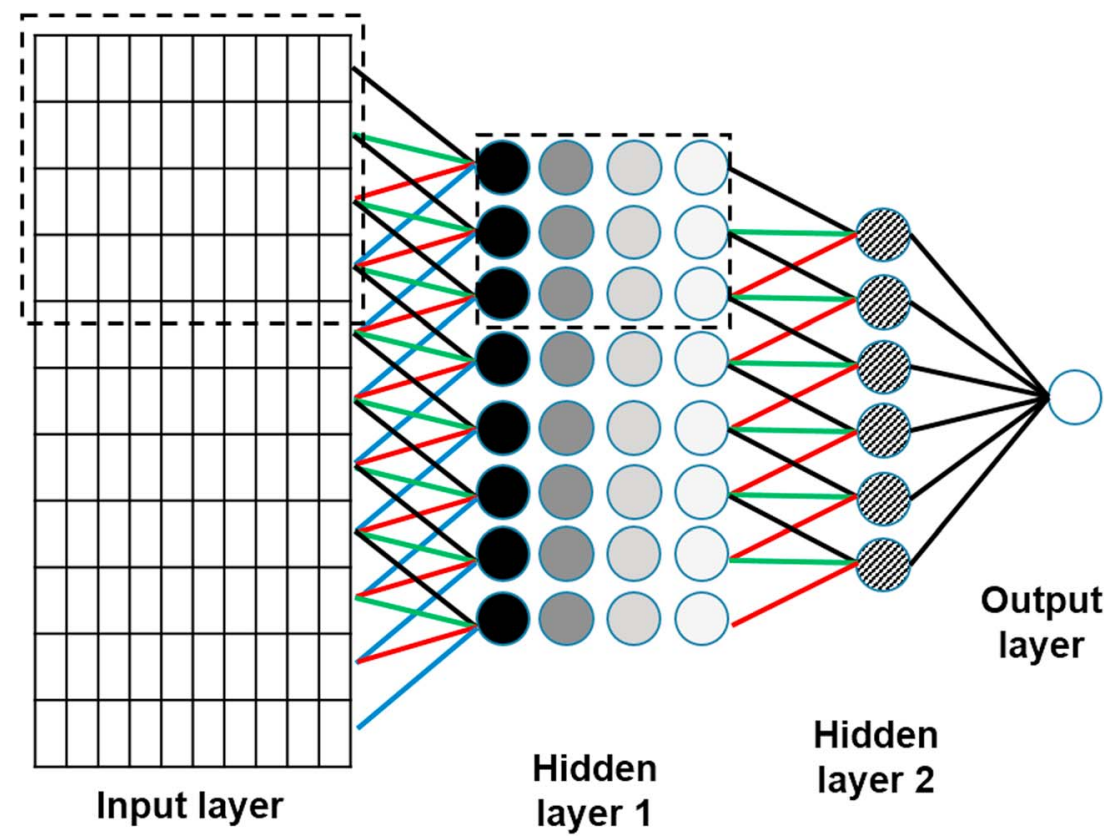

Figure A1. Feed-forward architecture of the NN system used onboard DEMETER. For the sake of simplicity each line between two layers represents all the connections between the corresponding rows. The different colored lines used identify the duplicated connections.

telemetry bit rate limitations onboard SC, the downloading of all whistler data is by no way an option. Consequently, the only remaining solution is to perform the identification and characterization of the whistlers onboard. Hereafter, we briefly present the RNF experiment which mainly consists of a Neural Network (NN) system implemented into the Digital Signal Processing unit of DEMETER to achieve this task (Lagoutte et al., 2003).

The NN unit is the neuron. The basic task fulfilled by a neuron is to sum its weighted inputs and to pass it through a nonlinear operator, usually a sigmoid function. A NN is a dense interconnection of neurons. For pattern recognition, one generally uses the multilayer perceptron architecture which is a feed-forward network with one input layer, one or more intermediate hidden layers and one output layer. To match a NN to a given classification task, several problems have to be solved. The first one is the choice of the input data (input layer) which must contain all the necessary information. The sec-

(a)

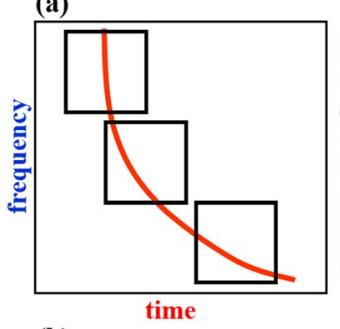

Input layers:

- 3 time resolutions: $T_{1}, T_{4}, T_{16}$ $\mathrm{dT}_{1}=6.4 \mathrm{~ms} ; \mathrm{dT}_{4}=4 \mathrm{dT}_{1} ; \mathrm{dT}_{16}=16 \mathrm{dT}_{1}$ - 4 frequency bands: $B 1, B 2, B 3, B 4$ $B 1=[3.2 \mathrm{kHz}-11 \mathrm{kHz}]$,

$\mathrm{B} 2=[2.4 \mathrm{kHz}-10.2 \mathrm{kHz}]$,

$\mathrm{B} 3=[4 \mathrm{kHz}-12 \mathrm{kHz}]$,

$\mathrm{B} 4=[5.5 \mathrm{kHz}-14 \mathrm{kHz}]$

(b)

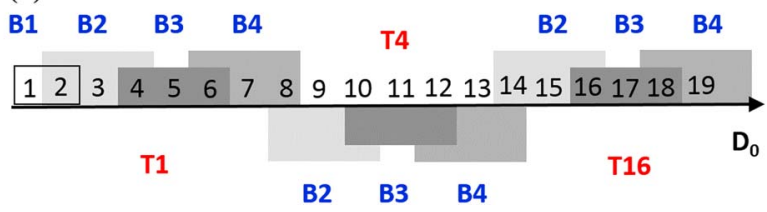

Figure A2. (a) The slope of the whistler signature in the input layer depends heavily on the time resolution and the frequency band chosen. (b)

Combining three distinct time resolutions with four sets of frequency bands, it is possible to identify up to 19 dispersion classes of whistlers. ond one is the choice of the parameters defining the NN architecture (number of hidden layers, number of neurons for a given hidden layer, etc.). The last problem is the training process which requires the building of a training data set and a validation data set. Both are composed of input layers for which the expected NN outputs are known. From the training data set, the NN connection weights relevant for the classification task are computed using the so-called back propagation algorithm. Eventually, the NN performances are evaluated using the validation data set.

The NN architecture used onboard DEMETER is shown in Figure A1. The input pattern is a 10 by 11 matrix (spectral coefficients). The output layer is composed of a unique neuron which takes the value +1 if a whistler is identified and -1 otherwise. The first hidden layer is composed of four duplicated neurons with a specialization window of four frames. The second hidden layer is composed of one duplicated neuron with a specialization window of three frames.

Playing with the time resolution and the frequency bands of the NN input pattern, one can change drastically the apparent slope of the whistlers. By 


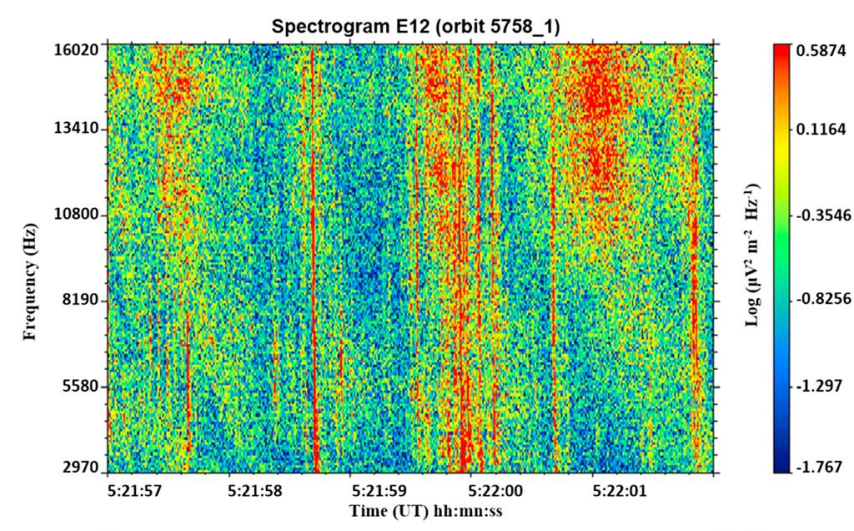

training the NN to identify whistler pattern corresponding to a given slope and by using three distinct time resolutions combined with four sets of frequency bands, it is possible to identify 19 classes of whistlers corresponding to dispersion parameters ranging from 0 to $300 \mathrm{~s}^{1 / 2}$ with a relative error of $10 \%$ (see Figure A2).

Before to be fully operational, the NN had to be trained and validated using electric field data measured on board DEMETER during burst mode. The training data base and validation data base used were composed of 2,500 input patterns and 1,500 input patterns, respectively. After training, the NN performance defined as the percentage of correct detection has been calculated to be equal to $91 \%$. Such a performance is not too far from what is usually achieved by trained human. It may not be good enough for case studies but this is certainly good enough for the statistical study discussed in this paper. The NN of DEMETER has been fully operational from June, 2005 till the end of the DEMETER mission.

An illustration of the agreement between the results provided by the NN and the characteristics of the whistlers encountered by DEMETER along its orbit is illustrated by the Figure A3. The upper panel is a VLF spectrogram representation of $5 \mathrm{~s}$ of the electric field recorded during nighttime condition. The bottom panel shows the corresponding NN results. The diamond symbols correspond to whistler identification. Along the vertical axis are the $19 D_{\mathrm{o}}$ classes that can be identified by the NN. The higher is the class the more dispersed is the associated whistler. One can see that the bursts of whistlers evidenced in the spectrogram are correctly identified both for the time location and the $D_{\mathrm{o}}$ estimation.

gure A3. (upper panel) VLF spectrogram (3 kHz-16 kHz) representation of $5 \mathrm{~s}$ of burst mode electric field data recorded onboard DEMETER during nighttime condition on 2 August 2005 (orbit 5758_1). (bottom panel)

Corresponding results provided by the NN system onboard DEMETER. Along the vertical axis are the 19 dispersion classes that can be identified by the NN. The diamond symbols correspond to whistler identification.

\section{Appendix B: The Electric Field Component Connected to the RNF}

The electric field component used by the RNF is perpendicular to the orbital plane of the SC, which, in view of the geometry of the problem, is suitable for the major part of the latitudinal span of the satellite orbit. Indeed, due to the refractive properties of the ionosphere, short-fractional hop whistlers enter the ionosphere with the vertical direction of the wave normal vector and, thus, propagate in the meridional plane. The polarization of the wave electric field is such that the larger half axis of the polarization ellipse lies in $\left(\mathrm{k}, \mathrm{B}_{0}\right)$-plane, that is, in meridional plane, making the angle $\alpha$ with the ambient magnetic field:

$$
\tan \alpha=\omega_{\mathrm{c}} / \omega \sin \theta,
$$

where $\omega_{\mathrm{c}}$ is the electron cyclotron frequency and $\theta$ is the propagation angle, that is, the angle between $\mathrm{k}$ and $\mathrm{B}_{0}$. Here and in the following estimation, we assume that the wave frequency is above the lower-hybrid resonance frequency, and the following inequalities are fulfilled: $\left.\omega / \omega_{c}<<1, \omega_{p}\right\rangle>\omega_{c}$, where $\omega_{p}$ is the electron plasma frequency, then the angle $\alpha$ is close to $\pi / 2$. The second half axis of the polarization ellipse is perpendicular to $\left(\mathrm{k}, \mathrm{B}_{0}\right)$-plane which coincides with the meridional plane. The ratio of the smaller half axis to the larger one is equal to

$$
\cos \theta-\omega / \omega_{c}
$$

At the DEMETER heights and with wave frequencies of the order of $10 \mathrm{kHz}, \omega / \omega_{\mathrm{c}} \sim 0.01$, so that the ratio of the polarization axes is close to $\cos \theta$. In the dipolar magnetic field, the vertical angle $\theta$ is connected with the latitude $\lambda$ by the relation

$$
\cos \theta=2 \sin \lambda /\left(1+3 \sin ^{2} \lambda\right)^{1 / 2}
$$

Thus, excepting close proximity to the equator, the component of the polarization vector perpendicular to the meridional plane is of the same order as the total electric field. Since the inclination of the DEMETER 
orbit is close to $98^{\circ}$, the orbital plane is close to the meridional one, and thus, the measured component is a proper presentation of the wave electric field.

\section{Acknowledgments}

This study was done in the frame of the GDRI "Helio-Plasmas" (joint CNRSRFBR project). D. S. acknowledges support from RFBR grant 19-02-00179. The work is mainly related to data recorded by the RNF experiment of the microsatellite DEMETER which was operated by the French Centre National d'Etudes Spatiales (CNES). The DEMETER data shown in this paper can be obtained at https://cdpp-archive. cnes.fr/ website. The F10.7-cm solar flux values are from http://sail.msfc. nasa.gov website.

\section{References}

Berthelier, J. J., Godefroy, M., Leblanc, F., Malingre, M., Menvielle, M., Lagoutte, D., et al. (2006). ICE, the electric field experiment on DEMETER. Planetary and Space Science, 54(5), 456-471.

Bourriez, F., Sauvaud, J. A., Pinçon, J. L., Berthelier, J. J., \& Parrot, M. (2016). A statistical study over Europe of the relative locations of lightning and associated energetic burst of electrons from the radiation belt. Annales Geophysicae, 34, 157-164.

Burkholder, B. S., Hutchins, M. L., McCarthy, M. P., Pfaff, R. F., \& Holzworth, R. H. (2013). Attenuation of lightning-produced sferics in the Earth-ionosphere waveguide and low-latitude ionosphere. Journal of Geophysical Research: Space Physics, 118, 3692-3699. https://doi. org/10.1002/jgra.50351

Buzzi, A. (2007). DEMETER satellite data analysis of seismo-electromagnetic signals, (PhD thesis). University Rome, Roma III, Italy.

Christian, H. J. (2003). Global frequency and distribution of lightning as observed from space by the Optical Transient Detector. Journal of Geophysical Research, 108(D1), 4005. https://doi.org/10.1029/2002JD002347

Chum, J., Jiřiček, F., Santolik, O., Parrot, M., Diendorfer, G., \& Fiser, J. (2006). Assigning the causative lightning to the whistlers observed on satellites. Annales Geophysicae, 24, 2921-2929.

Cohen, M. B., Lehtinen, N. G., \& Inan, U. S. (2012). Models of ionospheric VLF absorption of powerful ground based transmitters. Geophysical Research Letters, 39, L24101. https://doi.org/10.1029/2012GL054437

Collier, A. B., Lichtenberger, J., Clilverd, M. A., Rodger, C. J., \& Steinbach, P. (2011). Source region for whistlers detected at Rothera, Antarctica. Journal of Geophysical Research, 116, A03219. https://doi.org/10.1029/2010JA016197

Colman, J., \& Starks, M. (2013). VLF wave intensity in the plasmasphere due to tropospheric lightning. Journal of Geophysical Research: Space Physics, 118, 4471-4482. https://doi.org/10.1002/jgra.50217

Corcuff, Y., Corcuff, P., \& Tixier, M. (1966). Evolution de l'occurrence des sifflements radioélectriques entre maximum et minimum d'activité solaire. Comptes rendus de l'Académie des Sciences, 263, 584-587.

Cussac, T., Clair, M. A., Ultré-Guerard, P., Buisson, F., Lassalle-Balier, G., Ledu, M., et al. (2006). The DEMETER microsatellite and ground segment. Planetary and Space Science, 54(5), 413-427. https://doi.org/10.1016/j.pss.2005.10.013

Elie, F., Hayakawa, M., Parrot, M., Pinçon, J.-L., \& Lefeuvre, F. (1999). Neural network system for the analysis of transient phenomena on board the DEMETER micro-satellite. IEICE TRANSACTIONS on Fundamentals of Electronics, Communications and Computer Sciences, $82(8), 1575-1581$

Füllekrug, M., \& Fraser-Smith, A. C. (1997). Global lightning and climate variability inferred from ELF magnetic field variations. Geophysical Research Letters, 24, 2411-2414. https://doi.org/10.1029/97GL02358

Füllekrug, M., Mareev, E. A., \& Rycroft, M. J. (Eds.) (2006). Sprites, elves and intense lightning discharges. NATO Sciences Series. New York: Springer.

Gemelos, E. S., Inan, U. S., Walt, M., Parrot, M., \& Sauvaud, J. A. (2009). Seasonal dependence of energetic electron precipitation: Evidence for a global role of lightning. Geophysical Research Letters, 36, L21107. https://doi.org/10.1029/2009GL040396

Girish, T. E., \& Eapen, P. E. (2008). Geomagnetic and sunspot activity associations and ionospheric effects of lightning phenomena at Trivandrum near dip equator. Journal of Atmospheric and Solar-Terrestrial Physics, 70, 2222-2226.

Graf, K., Lehtinen, N., Spasojevic, M., Cohen, M., Marshall, R., \& Inan, U. (2013). Analysis of experimentally validated transionospheric attenuation estimates of VLF signals. Journal of Geophysical Research: Space Physics, 118, 2708-2720. https://doi.org/ $10.1002 /$ jgra.50228

Green, J. L., \& Inan, U. (2006). Chapter 4: Lightning effects on space plasmas and applications, Plasma Physics Applied, pp. 59-72.

Harrison, R. G., \& Usoskin, I. (2010). Solar modulation in surface atmospheric electricity. Journal of Atmospheric and Solar-Terrestrial Physics, 72(2-3), 176-182

Hayakawa, M. (1995). Whistlers. In H. Volland (Ed.), Handbook of Atmospheric Electrodynamics (pp. 165-204). CRC Press.

Hayakawa, M., Ohtsu, J., \& Iwai, A. (1971). Characteristics of dispersion and occurrence rate of whistlers at low latitudes during one solar cycle. Journal of Geomagnetism and Geoelectricity, 23(2), 187-204.

Hayakawa, M., Shimakura, S., Moriizumi, M., \& Ohta, K. (1992). On the location of causative atmospherics of very low latitude whistlers and their magnetospheric propagation mechanism. Radio Science, 27, 335-339.

Helliwell, R. (1993). 40 years of whistlers. In H. Matsumoto (Ed.), Modern Radio Science 1993 (pp. 189-212). New York: Oxford University Press.

Helliwell, R. A. (1965). Whistlers and Related Ionospheric Phenomena. Stanford University Press.

Holzworth, R. H., McCarthy, M. P., Pfaff, R. F., Jacobson, A. R., Willcockson, W. L., \& Rowland, D. E. (2011). Lightning-generated whistler waves observed by probes on the Communication/Navigation Outage Forecast System satellite at low latitudes. Journal of Geophysica Research, 116, A06306. https://doi.org/10.1029/2010JA016198

Inan, U. S., Piddyachiy, D., Peter, W. B., Sauvaud, J. A., \& Parrot, M. (2007). DEMETER satellite observations of lightning-induced electron precipitation. Geophysical Research Letters, 34, L07103. https://doi.org/10.1029/2006GL029238

Jacobson, A. R., Holzworth, R. H., Pfaff, R., \& Heelis, R. (2018). Coordinated satellite observations of the very low frequency transmission through the ionospheric $D$ layer at low latitudes, using broadband radio emissions from lightning. Journal of Geophysical Research: Space Physics, 123, 2926-2952. https://doi.org/10.1002/2017JA024942

Kumar, S., Siingh, D., Singh, R. P., Singh, A. K., \& Kamra, A. K. (2018). Lightning discharges, cosmic rays and climate. Surveys in Geophysics, 39, 861-899.

Lagoutte, D., Poirier, B., Colin, F., Elie, F., Legendre, C., \& Zamora, P. (2003). Micro-satellite DEMETER, charge utile scientifique, traitements des données bord, spécifications, Technical Note DMT-SP-7BS-6017-LPC-4.1 (in French)

McIlwain, C. E. (1961). Coordinates for mapping the distribution of magnetically trapped particles. Journal of Geophysical Research, 66(11), 3681-3691.

Miyahara, H., Kataoka, R., Mikami, T., Zaiki, M., Hirano, J., Yoshimura, M., et al. (2018). Solar rotational cycle in lightning activity in Japan during the 18-19 ${ }^{\text {th }}$ centuries. Annales Geophysicae, 36(2), 633-640. https://doi.org/10.5194/angeo-36-633-2018

Němec, F., Santolík, O., Parrot, M., \& Rodger, C. (2010). Relationship between median intensities of electromagnetic emissions in the VLF range and lightning activity. Journal of Geophysical Research, 115, A08315. https://doi.org/10.1029/2010JA015296

Neto, O. P., Pinto, I. R., \& Pinto, O. Jr. (2013). The relationship between thunderstorm and solar activity for Brazil from 1951 to 2009. Journal of Atmospheric and Solar-Terrestrial Physics, 98, 12-21. 
Nickolaenko, A. P., \& Hayakawa, M. (2002). Resonances in the Earth-ionosphere cavity (Vol. 19). Dordrecht-Boston-London: Kluwer Academic Publishers.

Nickolaenko, A. P., Koloskov, A. V., Hayakawa, M., Yampolski, Y. M., Budanov, O. V., \& Korepanov, V. E. (2015). 11-year solar cycle in Schumann resonance data as observed in Antarctica. Sun and Geosphere, 10(1), 39-49.

Ohta, K., \& Hayakawa, M. (1990). The correlation of whistler occurrence rate at a low latitude with thunderstorm activity at its conjugate region and with solar activity. Pure and Applied Geophysics, 133(1), 167-178.

Price, C. (2006). Global thunderstorm activity. In M. Füllekrug, et al. (Eds.), Sprites, elves and intense lightning discharges, NATO Sciences Series (pp. 85-99). New York: Springer.

Price, C., \& Rind, D. (1994). Possible implication of global climate change and global lightning distributions and frequencies. Journal of Geophysical Research, 99, 10,823-10,831. https://doi.org/10.1029/94JD00019

Reeve, N., \& Toumi, R. (1999). Lightning activity as an indicator of climate change. Quarterly Journal of the Royal Meteorological Society, 125, 893-903.

Santolík, O., Parrot, M., Inan, U. S., Burešová, D., Gurnett, D. A., \& Chum, J. (2009). Propagation of unducted whistlers from their source lightning: A case study. Journal of Geophysical Research, 114, A03212. https://doi.org/10.1029/2008JA013776

Sátori, G., Williams, E., \& Mushtak, V. (2005). Response of the Earth-ionosphere cavity resonator to the 11-year solar cycle in X-radiation. Journal of Atmospheric and Solar-Terrestrial Physics, 67(6), 553-562. https://doi.org/10.1016/j.jastp.2004.12.006

Shklyar, D. R., Chum, J., \& Jiřiček, F. (2004). Characteristic properties of Nu whistlers as inferred from observations and numerical modelling. Annales Geophysicae, 22(10), 3589-3606. https://doi.org/10.5194/angeo-22-3589-2004

Shklyar, D. R., Parrot, M., \& Titova, E. E. (2018). U-shaped spectrograms registered by the DEMETER satellite: observational features and formation mechanism. Journal of Geophysical Research: Space Physics, 123, 7077-7088. https://doi.org/10.1029/2018JA025656

Siingh, D., Kumar, P. R., Kulkarni, M. N., Singh, R. P., \& Singh, A. K. (2013). Lightning, convective rain and solar activity over the South/Southeast Asia. Atmospheric Research, 120, 99-111.

Siingh, D., Singh, A. K., Patel, R. P., Singh, R., Singh, R. P., Vennadhari, B., \& Mukherjee, M. (2008). Thunderstorm, lightning, sprites and magnetospheric whistler-mode waves. Surveys in Geophysics, 29, 499-551.

Siingh, D., Singh, R. P., Singh Ashok, K., Kulkarni, M. N., Gautam, A. S., \& Singh Abhay, K. (2011). Solar activity, lightning and climate. Surveys in Geophysics, 32, 659-703.

Smith, R. L., \& Angerami, J. J. (1968). Magnetospheric properties deduced from OGO 1 observations of ducted and nonducted whistlers. Journal of Geophysical Research, 73, 1-20.

Sonwalkar, V. S., Inan, U. S., Aggson, T. L., Farrell, W. M., \& Pfaff, R. (1995). Focusing of nonducted whistlers by the equatorial anomaly. Journal of Geophysical Research, 100(A5), 7783-7790.

Storey, L. R. O. (1953). An investigation of whistling atmospherics. Philosophical Transactions of the Royal Society A, $246(908), 113-141$. https://doi.org/10.1098/rsta.1953.0011

Stringfellow, M. F. (1974). Lightning incidence in Britain and the solar cycle. Nature, 249, 332-333.

Tarabukina, L., \& Kozlov Vladi, V. (2017). Spatial and temporal distribution of lightning strokes over North Asia and its comparison with solar activity variations in 2009-2016. Solar-Terrestrial Physics, 3(2), 65-69.

Thomson, N. R., Rodger, C. J., \& Clilverd, M. A. (2012). Tropical daytime lower D-region dependence on sunspot number. Journal of Geophysical Research, 117, A10306. https://doi.org/10.1029/2012JA018077

Toledo-Redondo, S., Parrot, M., \& Salinas, A. (2012). Variation of the first cut-off frequency of the Earth-ionosphere waveguide observed by DEMETER. Journal of Geophysical Research, 117, A04321. https://doi.org/10.1029/2011JA017400

Uman, M. A. (1986). All about lightning. New York, NY: Dover Publications.

Vavilov, D. I., \& Shklyar, D. R. (2014). Ionospherically reflected proton whistlers. Journal of Geophysical Research: Space Physics, 119, 9978-9991. https://doi.org/10.1002/2014JA020510

Williams, E. R. (1992). The Schumann resonance: A global tropical thermometer. Science, 256(5060), 1184-1187. https://doi.org/10.1126/ science.256.5060.1184

Williams, E. R. (2005). Lightning and climate: A review. Atmospheric Research, 76(1-4), 272-287. https://doi.org/10.1016/j. atmosres.2004.11.014

Záhlava, J., Nemec, F., Pinçon, J. L., Santolík, O., Kolmašová, I., \& Parrot, M. (2018). Whistler influence on the overall very low frequency wave intensity in the upper ionosphere. Journal of Geophysical Research: Space Physics, 123, 5648-5660. https://doi.org/10.1029/ 2017JA025137 